map will be able to find their position on the ground more rapidly, and because of constant scale it obviously has an advantage over mosaics.

In forestry, where mapping photogrammetrically is most difficult due to the dense overburden, the only conventional symbols that are feasible to plot are timber types, open swamps, open rock outcrops, etc., but having a photo image at scale the user will be able to recognize from the crown cover such points of detail that are impossible for an interpreter to plot.

The photo contour map can be produced showing contours, timber types, lot lines and any other detail that may be required such as boundaries or line work that is essential to the user.

The map is valuable for field navigation and, although it has not been used to any extent in Canada, it is felt that when this type of map is used in forestry, many other uses will evolve from them.

The advantages of the photo-contour map for forestry uses will be made known only when there have been sufficient maps employed in the industry.

The maps will not eliminate the forester, but will assist him in becoming more efficient in his work. Research is going on all the time and will eventually offer the ultimate in mapping.

Foresters can assist to a large degree in making known the problems to the author with their recommendations.

The photo-contour map was first produced by R. M. Towill Corporation, Ltd. in Hawaii, and is being used in many parts of the world today with great success in many other engineering fields.

\title{
1958 ANNUAL MEETING \\ PAPERS AND REPORTS ARE NOW AVAILABLE UPON REQUEST
}

Publication of all material presented at the 1958 Annual C.I.F. Meeting will not be possible. Members interested should, therefore, obtain a set of papers from:

Mr. G. L. MILLER,

P.O. Box 1120,

Fredericton, N.B. 